\title{
Mesoporous Silica Encapsulated Iron Oxide-Silver Heterodimeric Nanoparticles and Their Applications in Multi-Responsive Drug Release
}

\section{Xiaoting Sun}

China Medical University

Xiaohui Zhang

Northeastern University

Huazhe Yang

China Medical University

Xiaohong Wang ( $\nabla$ wangxiaohong709@163.com )

China Medical University

\section{Research}

Keywords: heterodimer nanoparticles, iron oxide, silver, mesoporous silica, drug release

Posted Date: September 27th, 2021

DOI: https://doi.org/10.21203/rs.3.rs-910453/v1

License: (c) (i) This work is licensed under a Creative Commons Attribution 4.0 International License. Read Full License 


\section{Abstract \\ Background}

Metal based nanomaterials play essential roles in the fields of cancer diagnosis and therapy, drug delivery and exploration. As a novel kind of metal nanocomposites, magnetic-plasmonic nanohybrids are promising candidates in combined therapy. However, few studies have demonstrated the multi-responsive drug delivery properties of the nanohybrids. In this work, novel $\mathrm{Fe}_{3} \mathrm{O}_{4}-\mathrm{Ag}$ heterodimer nanoparticles coated with mesoporous $\mathrm{SiO}_{2}$ were prepared for multi-responsive drug release applications.

\section{Results}

Seed growth method was employed to form the heterodimer particles, and a layer of mesoporous silica was coated on the particle to improve the biocompatibility of metal nanoparticles, which also acted as drug loading and release component. Characterized via infrared spectroscopy, X-Ray diffraction and transmission electron microscopy, the particles were confirmed to appear a Janus like structure with $\mathrm{Fe}_{3} \mathrm{O}_{4}$ and $\mathrm{Ag}$ hemispheres encapsulating in silica. Doxorubicin hydrochloride (DOX) was loaded on the surface of the particles for drug delivery. The drug loading efficiency, release performance and the apoptosis action of the particles on MCF-7 cells were investigated in vitro. The results showed that DOX was successfully loaded on the particles with encapsulation efficiency of $88.3 \%$ and drug loading of $30.6 \%$. And the release amount after $48 \mathrm{~h}$ increased from $10.05 \pm 0.19 \%$ to $68.53 \pm 8.20 \%$ as the environment was tuned to acidic, indicating an obvious $\mathrm{pH}$ response of the particles. Simultaneously, due to the photothermal effect of $\mathrm{Ag}$ hemispheres, the particles had exhibited an enhanced drug release stimulated by $808 \mathrm{~nm}$ near infrared (NIR) irradiation. And the results of apoptosis assay were in accord with the drug release profiles. Besides, the particles could well respond to an external magnetic field, which is beneficial to particle location or recovery.

\section{Conclusion}

The as-prepared particles exhibit good magnetic and photothermal properties originating from $\mathrm{Fe}_{3} \mathrm{O}_{4}$ and Ag hemispheres respectively, which are desired features in magnetic hyperthermia and photothermal therapy. The particles also possess $\mathrm{pH}$ and NIR light responsive drug release properties, enabling triggered and targeted drug delivery.

\section{Background}

According to the World Health Organization, about 10 million people worldwide have been suffering from cancer every year since 2003, and at least 6.2 million people would die annually of this disease [1]. In this context, the development of efficient and targeted treatments is receiving increasing attention. In recent years, nanomaterials have been widely applied in biomedical applications, particularly in the fields of 
drug delivery and bioimaging. Among numerous nanomaterials, metal nanoparticles hold broad application prospects in drug release and targeted therapy due to their desirable physical (e.g. plasmon resonance) and chemical (e.g. catalytic activity) properties [2,3]. In terms of diagnosis and therapy of cancer, metal nanoparticles hold unique advantages over other nanomaterials: easy to form nanostructures, flexible size control and simple modification. For instance, superparamagnetism, low toxicity and good biocompatibility can be found with iron oxide nanoparticles. They can orient and generate heat under the action of an external magnetic field, which can be applied to magnetic hyperthermia of tumor cells $[4,5]$, magnetic resonance imaging (MRI) $[6,7]$ and targeted drug delivery $[8$, 9]. While some noble metal nanoparticles, such as Au and Ag nanoparticles possess surface plasmon effect, and are capable of absorbing and scattering a portion of incident light, when applying this effect in cancer treatment, the absorbed light can kill tumor cells through photothermal effects, while the scattered light can be used for cell imaging $[10,11]$.

With the deepening of research, simplex treatment methods can no longer meet the clinical requirements, and therapy and imaging are expected to be integrated on one nanoplatform. The development of efficient, precise and personalized treatment has begun to flourish. For example, Hu et al [12] utilized a microemulsion method to mix hydrophobic magnetic nanoparticles and amphiphilic block polymers by ultrasonic emulsification, and asymmetric nanocomposites were obtained after evaporation of organic solvents. The particles exhibited a good magnetic response and could be applied in cell imaging. Controlled by an alternating magnetic field, the integration of detection and therapy of tumor cells were realized. Cui et al [13] prepared bovine serum albumin (BSA)-encapsulated Ag nanodots with a biomineralization method. Under the irradiation of $1.0 \mathrm{~W} / \mathrm{cm}^{2} 808 \mathrm{~nm}$ near-infrared light, the temperature could be raised to about $50^{\circ} \mathrm{C}$, which could effectively kill tumor cells by photothermal effect. While the particles possessed robust $X$-ray attenuation ( $5.7313 \mathrm{HU}$ per $\mathrm{mM} \mathrm{Ag}$ ), it allowed the particles to serve as computed tomography (CT) imaging agents, which had been proved on mice.

Many kinds of metal nanoparticles can play positive roles in tumor diagnosis and therapy, and synergistic effects and enhanced therapeutic performances can be achieved through constructing heterostructures. Among plentiful composite structures, the magnetic (e.g. iron oxide) - plasmonic (e.g. $\mathrm{Au}, \mathrm{Ag}$ ) nanohybrid is most attractive because the combination not only enables the inheritance of excellent surface chemistry, special optical and superparamagnetic properties from both components but also overcomes some limitations of conventional magnetic hyperthermia [14]. For example, Li et al [15] synthesized a therapeutic nanocomposite taking $\mathrm{Fe}_{3} \mathrm{O}_{4} / \mathrm{Ag}$ complex as the core and hollow gold as the shell, the composite nanoparticle possessed both nuclear magnetic imaging capability from magnetic particles and photothermal effect due to absorption in the infrared region. Xu et al [16] first generated oleate/oleylamine-coated $\mathrm{Au}-\mathrm{Fe}_{3} \mathrm{O}_{4}$ nanoparticles, and then the Pt complex was immobilized on the $\mathrm{Au}$ hemisphere, while Her2-specific monoclonal antibody, Herceptin, was attached to the $\mathrm{Fe}_{3} \mathrm{O}_{4}$ hemisphere. The formation of platin-Au- $\mathrm{Fe}_{3} \mathrm{O}_{4}$-Herceptin nanoparticles enabled the specific binding of platinum anticancer drugs to cancer cells, as well as the magnetic and optical tracing of Pt complexes in cells or organisms. Sotiriou et al [17] fabricated Janus like $\mathrm{Ag} / \mathrm{Fe}_{2} \mathrm{O}_{3}$ nanoparticles coated with a thin layer of 
$\mathrm{SiO}_{2}$ on the surface by flame aerosol technique, and applied the particles in tumor cell imaging and detection. $\mathrm{SiO}_{2}$ coated $\mathrm{Ag} / \mathrm{Fe}_{2} \mathrm{O}_{3}$ nanoparticles could not only maintain the original morphology, plasmonic and magnetic properties of the particles, but also block the contact between nano-silver and cells, therefore reduced the toxicity of Ag nanoparticles to living cells. In addition, the nanoparticles coated with the $\mathrm{SiO}_{2}$ shell could be stably dispersed in aqueous solutions and biological buffers, thereby effectively avoiding the problem of agglomeration and sedimentation or settling of the nanoparticles. Despite the achievements in magnetic-plasmonic nanohybrid fabrication, there are few systematical studies on the exploration of multiple functions of the composites. Especially the multi-response property which may be the most typical feature of nanocomposites, has not been adequately demonstrated for combined treatment of tumor.

Herein, multi-responsive and Janus type magnetic-plasmonic nanoparticles were designed to unfold the potential of this kind of nanocomposites in combination therapy of tumor. $\mathrm{Fe}_{3} \mathrm{O}_{4}$ and $\mathrm{Ag}$ were integrated to construct a multifunctional nanocomposite for multi-responsive chemotherapy. Due to lattice defects, $\mathrm{Fe}_{3} \mathrm{O}_{4}$ nanoparticles (NPs) were used as seeds to allow the growth of Ag NPs on the surface, and heterodimers were formed in a non-polar solution. To improve the biocompatibility of the particles, a layer of mesoporous silica was coated on particle surface. The nanocomposite particles enabled the integration of both characteristics of nano- $\mathrm{Fe}_{3} \mathrm{O}_{4}$ and nano-Ag, including magnetic responsibility and photothermal effect. While the silica shell could serve as a drug loading layer that would accomplish $\mathrm{pH}$ stimulated drug release. Application prospects of MRI and CT imaging can also be found with the particles, which are expected to achieve a combination of multiple treatments.

\section{Results}

The OA-modified $\mathrm{Fe}_{3} \mathrm{O}_{4} \mathrm{NPs}$ were positively charged, and the ligands transferred the lone pair electrons to the empty orbitals of the nanocrystal surface, while the silver nitrate and the oleylamine were mixed in priority to form positively charged Ag-OAm, and they were attracted by each other. Thus $\mathrm{Ag}^{+}$was concentrated on the surface of magnetic particles with $\mathrm{OA}$, and $\mathrm{Ag}$ was generated by free electron reduction on the surface of the magnetic particles. Once the initial silver domain was formed, the reduction of silver was accelerated under the autocatalytic action of $\mathrm{Ag}$. Once the electrons were completely consumed, the Ag reduction was completed, and Ag nanoparticles were formed at one end of the magnetic particles. The medium employed in the study was a non-polar solvent and could not supply electrons. Therefore, silver domain with a large surface was inhibited on the magnetic particle surface, such as forming core-shell structure, and finally a $\mathrm{Fe}_{3} \mathrm{O}_{4}$-Ag heterodimer was obtained [18].

The small-angle XRD patterns of $\mathrm{Fe}_{3} \mathrm{O}_{4} \mathrm{NPs}$ and $\mathrm{Fe}_{3} \mathrm{O}_{4}$-Ag dimers are shown in Fig. 1(a), it was clear that the diffraction peaks of $\mathrm{Fe}_{3} \mathrm{O}_{4} \mathrm{NPs}$ were located at $2 \theta$ of $30.38^{\circ}, 35.72^{\circ}, 43.34^{\circ}, 53.86^{\circ}, 57.28^{\circ}, 63.05^{\circ}$, respectively, corresponding to $\mathrm{Fe}_{3} \mathrm{O}_{4}$ crystal face (220), (311), (400), (422), (511), (440), respectively (JCPDS\#72-2303). In addition to the diffraction peak position of $\mathrm{Fe}_{3} \mathrm{O}_{4}$, diffraction peaks at $2 \theta$ of $35.75^{\circ}$, $43.45^{\circ}$ and $64.54^{\circ}$ occurred in the XRD pattern of $\mathrm{Fe}_{3} \mathrm{O}_{4}$-Ag particles, which corresponded to the (111), 
(200), (220) crystal faces of silver. The UV-visible absorption spectra of $\mathrm{Fe}_{3} \mathrm{O}_{4}-\mathrm{Ag}$ and pure $\mathrm{Fe}_{3} \mathrm{O}_{4}$ particles in Fig. 1(b) revealed that a significant absorption peak appeared near $440 \mathrm{~nm}$ with $\mathrm{Fe}_{3} \mathrm{O}_{4}-\mathrm{Ag}$ particles, which was the typical absorption wavelength of silver. Therefore, the existence of silver in the prepared dimer particles were confirmed by XRD and UV absorption patterns.

Functional groups on the surface of the as-prepared particles were characterized by Fourier transform infrared (FT-IR) spectroscopy to ensure the successful coating of oleic acid and silica, as shown in Fig. 2(a). From the FT-IR spectrum of oleic acid-coated $\mathrm{Fe}_{3} \mathrm{O}_{4} \mathrm{NPs}$, the peaks at wavenumbers of $2900 \mathrm{~cm}^{-1}$ and $2850 \mathrm{~cm}^{-1}$ corresponded to the vibration of -CH2- and -CH3- groups of oleic acid, the wave number of $1401 \mathrm{~cm}^{-1}$ corresponded to the $-\mathrm{CH}=\mathrm{CH}$ - vibration, and the wavenumber of $575 \mathrm{~cm}^{-1}$ indicated the $\mathrm{Fe}-\mathrm{O}$ vibration of oleic acid. Consequently, the magnetic particles containing Fe-O bond were successfully prepared, and the particle surface was coated with oleic acid, which made the $\mathrm{Fe}_{3} \mathrm{O}_{4} \mathrm{NPs}$ hydrophobic. From the FT-IR spectrum of silica coated heterodimers, the vibration peak of oleic acid at wave number of $1401 \mathrm{~cm}^{-1}$ disappeared, and the absorption peak at $575 \mathrm{~cm}^{-1}$ obviously weakened, while the absorption peak at $1100 \mathrm{~cm}^{-1}$ corresponding to the Si-O vibration of silica was dramatically enhanced. These results suggested that silica had indeed covered the surface of the heterodimers.

The surface of the silica shell was modified with a silanization agent. The amino group was first introduced to the surface of the silica, and then the amino group reacted with succinic anhydride to form the carboxyl group, which would provide the particles with pH sensitivity. Fig. 2(b) demonstrates the FT-IR spectra of the silica shells modified with amino and carboxyl groups on the surface respectively. Absorption peaks appeared at $1474 \mathrm{~cm}^{-1}$ and $695 \mathrm{~cm}^{-1}$ in the spectrum of amino modified silica corresponded to the bending vibration of the $\mathrm{NH}$ bond in amino group and the $-\mathrm{NH}_{3}{ }^{+}$symmetric vibration. After modifying carboxyl groups on the surface of the silica, the characteristic peaks of amino group disappeared or weakened, and the transverse longitudinal symmetrically contracted vibration peak of the Si-O-Si bond at $1101 \mathrm{~cm}^{-1}$ was enhanced, implying that part of the modifiers condensed with Si-OH groups. While the peak appearing at $1379 \mathrm{~cm}^{-1}$ signified the secondary amide -CO-NH- absorption band, confirming that the surface of the silica had been modified with carboxyl groups.

The morphology of $\mathrm{Fe}_{3} \mathrm{O}_{4}-\mathrm{Ag} @ \mathrm{SiO}_{2} \mathrm{NPs}$ were characterized by transmission electron microscopy (TEM) and energy dispersive spectrometer (EDS). Fig. 3(a) shows the TEM image of $\mathrm{Fe}_{3} \mathrm{O}_{4} \mathrm{NPs}$, the particles are spherical, and the particle size is about $10 \mathrm{~nm}$ and generally uniform. Fig. 3(b) shows the TEM image of $\mathrm{Fe}_{3} \mathrm{O}_{4}$-Ag heterodimers and the particles appear clear asymmetry. Ag NPs had grown on the surface of $\mathrm{Fe}_{3} \mathrm{O}_{4} \mathrm{NPs}$ to form a dumbbell-shaped morphology, and the size of Ag particles is about $8 \mathrm{~nm}$. Fig. 3(c) shows the TEM image of $\mathrm{Fe}_{3} \mathrm{O}_{4}-\mathrm{Ag} @ \mathrm{SiO}_{2} \mathrm{NPs}$. The image exhibits that an asymmetric core is wrapped in the silica shell, the particles are spherical, and the particle size is between $80-100 \mathrm{~nm}$ with a narrow distribution. The elemental analysis map of $\mathrm{Fe}_{3} \mathrm{O}_{4}-\mathrm{Ag} @ \mathrm{SiO}_{2} \mathrm{NPs}$ was obtained from EDS (Fig. 3(d)). The finally prepared particles contain the elements of $\mathrm{Ag}$, $\mathrm{Fe}$ and $\mathrm{Si}$, affirming that the heterodimers were indeed encapsulated in the silica shells. 
The magnetism of the as-prepared nanoparticles was measured and tested by magnetometer and a magnetic field. The hysteresis loop diagrams of $\mathrm{Fe}_{3} \mathrm{O}_{4} \mathrm{NPs}$ and $\mathrm{Fe}_{3} \mathrm{O}_{4}-{\mathrm{Ag} @ S i O_{2}} \mathrm{NPs}$ are given in Fig. 4(a). The saturation magnetization of $\mathrm{Fe}_{3} \mathrm{O}_{4}$ and $\mathrm{Fe}_{3} \mathrm{O}_{4}-\mathrm{Ag} @ \mathrm{SiO}_{2} \mathrm{NPs}$ was $66.71 \mathrm{emu} / \mathrm{g}$ and 49.39 emu/g respectively. Compared to pure $\mathrm{Fe}_{3} \mathrm{O}_{4}$, the magnetization of the nanocomposite was slightly reduced due to the encapsulation with silica on the surface, still the nanocomposites could well respond to an external magnetic field, as displayed in Fig. 4(b). $\mathrm{Fe}_{3} \mathrm{O}_{4}-\mathrm{Ag} @ \mathrm{SiO}_{2} \mathrm{NPs}$ dispersed in ethanol solution were attracted by a magnet, and the particles were completely adsorbed within $1 \mathrm{~min}$. Therefore, the asprepared $\mathrm{Fe}_{3} \mathrm{O}_{4}-\mathrm{Ag} @ \mathrm{SiO}_{2} \mathrm{NPs}$ can be easily separated from matrix, which allows for the in vivo location or recovery of the particles controlled by a magnetic field.

\section{Drug loading and releasing}

DOX is one of the most widely used chemotherapeutic drugs in cancer therapy. DOX is positively charged, while the surface of modified $\mathrm{Fe}_{3} \mathrm{O}_{4}-\mathrm{Ag} @ \mathrm{SiO}_{2} \mathrm{NPs}$ is negatively charged, thus DOX can be loaded on the surface of silica by electrostatic interaction. The encapsulation efficiency of the particles was calculated to be $85.7 \pm 2.1 \%$, and the drug loading was $30.0 \pm 0.5 \%$. Fig. 5(a) illustrates the Raman spectra of free DOX and DOX-loaded particles. The peak locations of both spectra are generally the same, hence it could be deduced that DOX was loaded on the particles. In order to avoid the side effects and enhance the efficacy of anticancer drugs, drug delivery systems should be endowed with the ability of controlled drug release. By modifying carboxyl group on the surface of $\mathrm{Fe}_{3} \mathrm{O}_{4}-\mathrm{Ag} @ \mathrm{SiO}_{2} \mathrm{NPs}$, the loaded drug would be released rapidly in an acidic environment, such as tumor tissues.

Fig. 5(b) presents the in vitro drug release profiles of the particles at different $\mathrm{pH}$ values, at $\mathrm{pH} 7.4$, the cumulative release of the drug was $10.0 \pm 0.2 \%$, and at $\mathrm{pH} 5.4$, the cumulative release of DOX reached $68.5 \pm 8.2 \%$, which is about 6 times higher than that at $\mathrm{pH} 7.4$. This result indicates that the obtained particles were produced with $\mathrm{pH}$ responsibility by surface modification with the carboxyl groups, and the drug release profile at acidic environment was quite different from that at neutral environment. Actually, the carboxyl groups were attached on the surface of the silica shell, and in neutral solutions, DOX could firmly attach on the particles due to the strong electronegativity actions. When the environment was converted to acidic, the electronegativity of the particles weakened and the particle surface gradually converted to positively charged, thus the adsorption capacity of DOX weakened [19]. Compared with normal tissues, tumor tissue has a lower $\mathrm{pH}$ value and is weakly acidic [20]. Therefore, the $\mathrm{pH}$ sensitive drug carriers may reduce the side effects on normal tissues because massive drug leakage would not occur under neutral pH conditions. When the carriers enter a tumor tissue with a slightly acidic environment, the anticancer drugs can be effectively released, improving the efficacy of anticancer drugs.

\section{Cytotoxicity of the particles}

Biocompatibility is one of the prerequisites for drug delivery systems to ensure that the carriers will not affect the growth and reproduction of normal cells. A MTT assay was carried out to test the biocompatibility of the prepared particles, and the results are shown in Fig. 6 . For blank particles at the 
concentration ranging from 0 to $100 \mu \mathrm{g} / \mathrm{mL}$, the viability of MCF-7 cells was maintained above $95 \%$ after co-incubation with the particles for $24 \mathrm{~h}$. Therefore, no obvious cytotoxicity was found with the particles at the given doses. For DOX loaded particles at the concentration ranging from 0.1 to $100 \mu \mathrm{g} / \mathrm{mL}$, the cell viability decreased from $90.0 \pm 8.7 \%$ to $30.5 \pm 3.2 \%$ with the increase of particle concentration. The results demonstrate that the drug was effectively released in MCF-7 cells and the particles had promoted the apoptosis of MCF-7 cells in a dose-dependent manner.

In order to clarify the performance of the particles on cells, MCF-7 cells were stained with Calcein-AM and propidium iodide (PI) for fluorescent imaging. The results are shown in Fig. 7. The morphology of cells cultured with blank particles is similar to that of the control group (without particles or drug). Green fluorescence (indication of living cells) is evident and red fluorescence (indication of apoptotic cells) does not appear, suggesting that the cells were in regular growth state, with few cells in the middle and late stages of decline. For the cells co-cultured with drug-loaded particles, the morphology of the cells observed under bright field deforms into rounded shape. The intensity of green fluorescence is dramatically decreased and red fluorescence emerges obviously, indicating that the number of cells in the middle and late stages of decline was increased. This result is in accord with the cytotoxicity test, thus it can be concluded that DOX was effectively released from the particles and successfully induced cell apoptosis.

\section{NIR assisted drug release}

Since Ag NPs with an average diameter of $8 \mathrm{~nm}$ were embodied in the $\mathrm{Fe}_{3} \mathrm{O}_{4}-\mathrm{Ag} @ \mathrm{SiO}_{2} \mathrm{NPs}$, heat can be generated under the irradiation of $808 \mathrm{~nm}$ NIR laser through the well-known photothermal effect of $\mathrm{Ag}$ NPs, which would also promote the release of the drug and accelerate the decline of MCF-7 cells. Fig. 8 exhibits the images of MCF-7 cells treated with blank particles and drug-loaded particles after NIR irradiation. For cells irradiated by NIR laser, the shapes of the cells are regular. Meanwhile, green fluorescence is palpable and red fluorescence is absent, implying that NIR laser had not affected the cell growth. For the cells co-cultured with $\mathrm{Fe}_{3} \mathrm{O}_{4}-\mathrm{Ag} @ \mathrm{SiO}_{2}$ particles, the green fluorescence is slightly decreased and a few cells appear red fluorescence. This phenomenon indicates that after laser irradiation, heat generated by the NPs had killed some of the MCF-7 cells, but there was no extensive apoptosis. However, for the cells co-cultured with the drug-loaded particles, the cells deform after irradiation with green fluorescence almost extinguished, in the contrary, red florescence greatly lightened, indicating that the majority of the cells were apoptotic. Compared with the cells which had not been treated with laser irradiation, the apoptosis rate of the NIR treated cells was enhanced. In conclusion, the local heat generated by the particles was conducive to the rapid release of DOX and accelerated the apoptosis of MCF-7 cells.

\section{Discussion}


The type of magnetic-plasmonic hybrid nanoparticles hold great promise in tumor imaging, magnetic hyperthermia and photothermal therapy. A variety of studies have fabricated this kind of particles via various methods and revealed their potential to act as the contrast agents in MRI and CT imaging, and heat generating components in enhanced or combined thermal therapy using magnetic field or light. And core-shell structure is most frequently employed when fabricating the nanoparticles, despite the potential of Janus structure having different hemispheres that will give full play to their strengths independently. Therefore, the present work has demonstrated the fabrication of Janus like $\mathrm{Fe}_{3} \mathrm{O}_{4}$-Ag NPs which are expected to accomplish the missions of magnetic response and photo-thermal conversion respectively and simultaneously in a non-interference manner. Facing the challenge of developing nanoplatforms with multiple diagnostic and therapeutic functions, drug delivery (with drug loading and controlled release) was endowed to the proposed $\mathrm{Fe}_{3} \mathrm{O}_{4}-\mathrm{Ag} \mathrm{NPs}$, which is believed to be the icing on the cake. Here the silica layer on the particle acted as not only the isolating film to avoid the potential toxicity of Ag NPs, but also the carrier for drug loading and controlled release. Thus triple functions (magnetic manipulation, photothermal effect and drug delivery) can be found with the nanoparticles developed in this work. Still there is space for this work to be further improved. For instance, the potential of the particles to serve as the contrast agents in MRI or CT imaging had not been adequately explored in vivo, although the particles are promising in these fields contributing to the inherent features of metal NPs contained in the particles. Hence efforts may be devoted to unfold the availability of the particles in live models in the future work.

\section{Conclusions}

Here we fabricated a novel kind of hybrid $\mathrm{Fe}_{3} \mathrm{O}_{4}-\mathrm{Ag} @ \mathrm{SiO}_{2}$ NPs with the properties of magnetism, photothermy and controlled drug delivery. Seed growth method was employed to generate the Janus type $\mathrm{Fe}_{3} \mathrm{O}_{4}$-Ag NPs and the morphology and size of the particles were confirmed and characterized. In order to avoid cytotoxicity of the particles, a layer of mesoporous silica was coated on the particle surface. Experimental results indicated that the silica shell did not affect the magnetism of the particles obviously, and could serve as an efficient drug delivery component. High encapsulation efficiency and drug loading of DOX were obtained with the particles, and $\mathrm{pH}$ stimulated drug release was observed due to the existence of carboxyl group on silica shell. The cytotoxicity and intracellular drug release experiments demonstrated that the nanoparticles were biocompatible, and the drug was effectively released into cells to induce cell apoptosis, which could be further promoted by NIR laser irradiation. The proposed NPs are expected to have presented a comprehensive function in antitumor application, including drug delivery, photothermal therapy and magnetic control which can be further explored for magnetic targeting, magnetic hyperthermia and CT imaging. It is believed that more advanced functions will be developed and integrated on these hybrid nanoparticles to achieve progressed treatment effects in fighting against tumor.

\section{Methods}

\section{Reagents}


Ferric trichloride, ferrous sulfate, ammonium hydroxide, $\mathrm{n}$-hexane, isopropyl alcohol, tetraethyl orthosilicate (TEOS), cetyl trimethyl ammonium bromide (CTAB), anhydrous sodium carbonate, $\mathrm{N}$, ' $\mathrm{N}$ dimethyl formamide, butanedioic anhydride and octane were purchased from Sinopharm Chemical Reagent Corporation, Shanghai, China. Oleic acid (OA), oleylamine (OAm) and 3-

aminopropyltrimethoxysilane (ATPES) were purchased from Aladdin Industrial Corporation, Shanghai, China. Silver nitrate, propidium iodide (PI) was purchased from Shanghai yuanye Bio-Technology Co., Ltd., Calcein-AM was purchased from Yeasen Biotech Co., Ltd., Shanghai, China. Methylthiazolydiphenyltetrazolium bromide (MTT) was purchased from Dalian Meilun Biotechnology Co., Ltd., China. All of the above reagents were used as received without further purification, and deionized water was used throughout the experiment.

\section{Preparation of OA-modified $\mathrm{Fe}_{3} \mathrm{O}_{4} \mathrm{NPs}$.}

OA-coated $\mathrm{Fe}_{3} \mathrm{O}_{4}$ NPs were prepared by a chemical co-precipitation method [21]. In brief, $12 \mathrm{mmol} \mathrm{FeCl}$ and $6 \mathrm{mmol} \mathrm{FeSO}_{4}$ were dissolved in $80 \mathrm{~mL}$ of deionized water, and the mixture was heated to $40{ }^{\circ} \mathrm{C}$ in a water bath and $16 \mathrm{~mL}$ of ammonia water was added. After heating to $80^{\circ} \mathrm{C}, 5 \mathrm{~mL}$ of OA was added and reacted for $2 \mathrm{~h}$. The product was collected by magnetic separation, then dissolved in n-octane, and the precipitate was removed by suction filtration. The supernatant was precipitated with excess absolute ethanol, and the precipitate was washed with anhydrous ethanol and deionized water alternately, and dried in vacuum.

\section{Preparation of $\mathrm{Fe}_{3} \mathrm{O}_{4}$-Ag NPs.}

Silver nitrate $(34 \mathrm{mg})$ and oleylamine $(800 \mu \mathrm{L})$ were dispersed in $15 \mathrm{~mL}$ of $\mathrm{n}$-hexane, under $70{ }^{\circ} \mathrm{C}$ and mixing, $1 \mathrm{~mL}$ of $\mathrm{OA}$-coated $\mathrm{Fe}_{3} \mathrm{O}_{4}$ dispersion (in n-hexane, $5 \mathrm{mg} / \mathrm{mL}$ ) was added, and the temperature was set to $80{ }^{\circ} \mathrm{C}$, reacted for $2 \mathrm{~h}$. After reaction, the mixture was cooled down to room temperature, excess ethanol was added for precipitation, and the precipitate was washed with ethanol and dried in vacuum.

\section{Preparation of $\mathrm{Fe}_{3} \mathrm{O}_{4}-\mathrm{Ag} @ \mathrm{SiO}_{2} \mathrm{NPs}$.}

$50 \mathrm{mg}$ of $\mathrm{Fe}_{3} \mathrm{O}_{4}$-Ag particles was dispersed in $20 \mathrm{~mL}$ of isopropanol and sonicated for $15 \mathrm{~min}$. Under 40 ${ }^{\circ} \mathrm{C}$ and $300 \mathrm{rpm}$ stirring, $1.8 \mathrm{~mL}$ of deionized water and $1 \mathrm{~mL}$ of ammonia water were added, and after 10 min of reaction, $50 \mu \mathrm{L}$ of TEOS was injected to the mixture. After $2 \mathrm{~h}$ reaction, the particles were washed with ethanol and water. Then the particles were dispersed in $10 \mathrm{~mL}$ water and sonicated for $15 \mathrm{~min}$, then transferred to a mixed solution of $15 \mathrm{~mL}$ water, $15 \mathrm{~mL}$ ethanol and $0.275 \mathrm{~mL}$ ammonia water with $75 \mathrm{mg}$ CTAB, and stirred at room temperature for $30 \mathrm{~min}$ at $300 \mathrm{rpm}$. Afterwards, $125 \mu \mathrm{L}$ TEOS was added to the dispersion and stirred for $6 \mathrm{~h}$, and the particles were washed alternately with ethanol and water. The particles were ultrasonically dispersed with $424 \mathrm{mg}$ of sodium carbonate in $20 \mathrm{~mL}$ of water, reacted at 50 ${ }^{\circ} \mathrm{C}$ for $10 \mathrm{~h}$, and washed alternately with deionized water and ethanol. The particles were then dispersed in $15 \mathrm{~mL}$ of water, transferred to a reaction vessel and reacted at $100^{\circ} \mathrm{C}$ for $2 \mathrm{~h}$. Last the particles were washed with deionized water and dried in vacuum. 


\section{Particle surface modification.}

For amino group modification, $10 \mathrm{mg}$ of the particles were dispersed in $30 \mathrm{~mL}$ of ethanol, $1 \mathrm{~mL}$ of ATPES was dispersed in $10 \mathrm{~mL}$ of ethanol, these dispersions were mixed and stirred at room temperature for $8 \mathrm{~h}$, then the mixture was heated to $105^{\circ} \mathrm{C}$ and refluxed for $2 \mathrm{~h}$. For carboxyl group modification, $10 \mathrm{mg}$ particles were dispersed in $50 \mathrm{~mL} \mathrm{~N}, \mathrm{~N}$-dimethylformamide containing $2 \mathrm{wt} \%$ succinic anhydride, and the mixture was stirred at room temperature for $24 \mathrm{~h}$, and the particles were collected and washed with absolute ethanol, last dried in vacuum before use.

The overall preparation process of $\mathrm{Fe}_{3} \mathrm{O}_{4}-\mathrm{Ag} @ \mathrm{SiO}_{2} \mathrm{NPs}$ is presented in Scheme 1.

\section{Drug loading and in vitro release}

$1 \mathrm{mg}$ of nanoparticles were dispersed in $1 \mathrm{~mL}$ of phosphate buffer saline (PBS, with DOX, at a concentration of $0.5 \mathrm{mg} / \mathrm{mL}$ ) and stirred for $8 \mathrm{~h}$. After the particles were magnetically separated, the UV absorbance of the solution was measured at $480 \mathrm{~nm}$ to deduce the encapsulation efficiency and drug loading, and they can be calculated by using the following formulas:

Encapsulation efficiency (\%) $=$ Weight $t_{\text {loaded Dox }} /$ Weight total Dox $\times 100 \%$

Drug loading (\%) =Weight ${ }_{\text {loaded Dox }} /$ Weight $\mathrm{Fe}_{3} \mathrm{O}_{4}-{\mathrm{Ag} @ \mathrm{SiO}_{2}}_{2} / \mathrm{DOX} \times 100 \%$

For plotting drug release profiles, $1 \mathrm{mg}$ of drug-loaded particles were dispersed in $3 \mathrm{~mL}$ of neutral PBS (pH

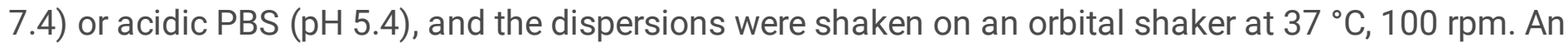
aliquot of the supernatant was taken at intervals and the corresponding release medium was replenished in time. The UV absorbance of the removed supernatant was measured at a wavelength of $480 \mathrm{~nm}$, and the cumulative release amount of the drug at each time point was calculated, and each sample was measured three times in parallel.

\section{Cell apoptosis.}

MCF-7 cells were chosen for cytotoxicity test and apoptosis study. Toxicity of blank particles was tested by MTT method, briefly, cells were first transplanted to a 96-well plate with a density of $10^{4}$ cells per well, and cells in each well were incubated with $100 \mu \mathrm{L}$ of culture medium (Dulbecco's modified Eagle's medium with fetal bovine serum and antibiotics) at $37^{\circ} \mathrm{C}$ for $24 \mathrm{~h}$. Then the medium in each well was replaced by $100 \mu \mathrm{L}$ of fresh medium (free of fetal bovine serum) or medium in which the particles were dispersed to a concentration of $0.1,0.5,1,5,10,50,100 \mu \mathrm{g} / \mathrm{mL}$. After a subsequent incubation for $48 \mathrm{~h}$, the particle suspensions were discarded, and the wells were washed twice with PBS. $80 \mu \mathrm{L}$ of the medium and $20 \mu \mathrm{L}$ of MTT solution $(5 \mathrm{mg} / \mathrm{mL}$ ) were added into each well followed by $4 \mathrm{~h}$ incubation. Afterwards, the solution in each well was discarded, $100 \mu \mathrm{L}$ of dimethyl sulfoxide was added and shaken for $10 \mathrm{~min}$ on an orbital shaker. Lastly, the absorbance at $490 \mathrm{~nm}$ of the solution in each well was measured for cell viability estimation using a microplate reader (SynergyH1, BioTec, USA). Cells cultured with particle-free 
media were used as references. For cell apoptosis study, DOX loaded particles $(0.1,0.5,1,5,10,50,100$ $\mu \mathrm{g} / \mathrm{mL}$, with a drug loading of $28.4 \%$ ) were used instead of blank particles.

\section{Cell imaging.}

Calcein-Am and propidium iodide (PI) were used as dyes to indicate the living cells and the middle and late apoptotic cells respectively. The MCF-7 cell suspension was planted in a 24-well plate at a concentration of about $300 \mu \mathrm{L}$ per well and incubated for $24 \mathrm{~h}$. Then blank particles and DOX loaded particles were added into the culture medium and co-incubated for another $24 \mathrm{~h}$. Afterwards, the culture medium was discarded, and the cells were washed with PBS, then $50 \mu \mathrm{L}$ of $10 \mu \mathrm{g} / \mathrm{mL}$ Calcein-Am was added to each well and cultured for $15 \mathrm{~min}$. Subsequently the cells were washed twice with PBS, followed by adding $50 \mu \mathrm{L}$ of $20 \mu \mathrm{g} / \mathrm{mL}$ PI to each well and culturing for $10 \mathrm{~min}$. Last the cells were washed twice with PBS and were placed under an inverted fluorescence microscope (Ti-U, Nikon, Japan) for observation.

\section{NIR laser assisted cell apoptosis.}

The MCF-7 cell suspension was planted in a 24-well plate at a concentration of about $300 \mu \mathrm{L}$ per well and incubated for $24 \mathrm{~h}$, and the medium was discarded, $300 \mu \mathrm{L}$ of culture medium having blank particles or DOX loaded particles were added. The cells were irradiated with $808 \mathrm{~nm}$ laser at an intensity of 0.84 $\mathrm{w} / \mathrm{cm}^{2}$ for $5 \mathrm{~min}$, and then cultured for $24 \mathrm{~h}$. After discarding the medium and washing with PBS, $50 \mu \mathrm{L}$ of $10 \mu \mathrm{g} / \mathrm{mL}$ Calcein-Am was added to each well and cultured for $15 \mathrm{~min}$, then each well was washed twice with PBS, and added with $50 \mu \mathrm{L} 20 \mu \mathrm{g} / \mathrm{mL}$ PI followed by another culturing for $10 \mathrm{~min}$. Lastly, the wells were washed twice with PBS, and the cells were observed under an inverted fluorescence microscope.

\section{Abbreviations}

DOX: Doxorubicin hydrochloride; NIR: Near infrared; MRI: Magnetic resonance imaging; BSA: Bovine serum albumin; CT: Computed tomography; NPs: Nanoparticles; FT-IR: Fourier transform infrared; TEM: Transmission electron microscopy; EDS: Energy dispersive spectrometer; TEOS: Tetraethyl orthosilicate; CTAB: Cetyl trimethyl ammonium bromide; OA: Oleic acid; OAm: Oleylamine; ATPES: 3-

aminopropyltrimethoxysilane; PI: Propidium iodide; MTT: Methylthiazolydiphenyl-tetrazolium bromide; PBS: Phosphate buffer saline.

\section{Declarations}

\section{Ethics approval and consent to participate}

Not applicable.

\section{Consent for publication}


The founding sponsors had no role in the design of the study; in the collection, analyses, or interpretation of data; in the writing of the manuscript, and in the decision to publish the results.

\section{Availability of data and materials}

The data that support the findings of this study are available from the corresponding author upon reasonable request.

\section{Competing interests}

The authors declare no conflict of interest.

\section{Funding}

The work was supported by grants from the National Natural Science Foundation of China (NSFC) (Nos. 21375012, 81571832), the Key Research \& Development Project of Liaoning Province (No. 2018225082), and the 2018 Scientist Partners of China Medical University (CMU) and Shenyang Branch of Chinese Academy of Sciences (CAS) (No. HZHB2018013).

\section{Authors' contributions}

XS performed the experiments and generated the data. XZ made substantial contributions to the conception and design of the present study. HY and XW contribute to the drafting and revision of the manuscript. All authors read, revised and approved the manuscript and agreed to be accountable for all aspects of the research in ensuring that the accuracy or integrity of any part of the work are appropriately investigated and resolved.

\section{Acknowledgements}

This work received kind assistance from Northeastern University (Shenyang).

\section{References}

1. McGuire S. World Cancer Report 2014. Geneva, Switzerland: World Health Organization, International Agency for Research on Cancer, WHO Press, 2015. Adv Nutr. 2016;7:418-9.

2. Cole AJ, Yang VC, David AE. Cancer theranostics: the rise of targeted magnetic nanoparticles. Trends Biotechnol. 2011;29:323-32.

3. Kuchur OA, Tsymbal SA, Shestovskaya MV, Serov NS, Dukhinova MS, Shtil AA. Metal-derived nanoparticles in tumor theranostics: Potential and limitations. J Inorg Biochem. 2020;209:111117.

4. Zanganeh S, Hutter G, Spitler R, Lenkov O, Mahmoudi M, Shaw A, Pajarinen JS, Nejadnik H, Goodman $\mathrm{S}$, Moseley $\mathrm{M}$, et al. Iron oxide nanoparticles inhibit tumour growth by inducing pro-inflammatory macrophage polarization in tumour tissues. Nat Nanotechnol. 2016;11:986-94. 
5. Li X, Li W, Wang M, Liao Z. Magnetic nanoparticles for cancer theranostics: Advances and prospects. J Controlled Release. 2021;335:437-48.

6. Espinosa A, Di Corato R, Kolosnjaj-Tabi J, Flaud P, Pellegrino T, Wilhelm C. Duality of Iron Oxide Nanoparticles in Cancer Therapy: Amplification of Heating Efficiency by Magnetic Hyperthermia and Photothermal Bimodal Treatment. Acs Nano. 2016;10:2436-46.

7. Farzin A, Etesami S, Quint J, Memic A, Tamayol A. Magnetic Nanoparticles in Cancer Therapy and Diagnosis. Adv Healthc Mater. 2020;9:2192-659.

8. Lopes G, Vargas JM, Sharma SK, Beron F, Pirota KR, Knobel M, Rettori C, Zysler RD. Ag-Fe304 Dimer Colloidal Nanoparticles: Synthesis and Enhancement of Magnetic Properties. J Phys Chem C. 2010;114:10148-52.

9. Zhao S, Yu X, Qian Y, Chen W, Shen J. Multifunctional magnetic iron oxide nanoparticles: an advanced platform for cancer theranostics. Theranostics. 2020;10:6278-309.

10. Abbasi E, Milani M, Aval SF, Kouhi M, Akbarzadeh A, Nasrabadi HT, Nikasa P, Joo SW, Hanifehpour Y, Nejati-Koshki K, Samiei M. Silver nanoparticles: Synthesis methods, bio-applications and properties. Crit Rev Microbiol. 2016;42:173-80.

11. Singh P, Pandit S, Mokkapati VRSS, Garg A, Ravikumar V, Mijakovic I. Gold Nanoparticles in Diagnostics and Therapeutics for Human Cancer. Int J Mol Sci 2018;19:1979.

12. Hu S-H, Gao X. Nanocomposites with Spatially Separated Functionalities for Combined Imaging and Magnetolytic Therapy. J Am Chem Soc. 2010;132:7234-7.

13. Cui Y, Yang J, Zhou Q, Liang P, Wang Y, Gao X, Wang Y. Renal Clearable Ag Nanodots for in Vivo Computer Tomography Imaging and Photothermal Therapy. ACS Appl Mater Interfaces. 2017;9:59006.

14. Cazares-Cortes E, Cabana S, Boitard C, Nehlig E, Griffete N, Fresnais J, Wilhelm C, Abou-Hassan A, Menager C. Recent insights in magnetic hyperthermia: From the "hot-spot" effect for local delivery to combined magneto-photo-thermia using magneto-plasmonic hybrids. Adv Drug Delivery Rev. 2019;138:233-46.

15. Lin AY, Young JK, Nixon AV, Drezek RA. Encapsulated Fe304/Ag Complexed Cores in Hollow Gold Nanoshells for Enhanced Theranostic Magnetic Resonance Imaging and Photothermal Therapy. Small. 2014;10:3246-51.

16. Xu C, Wang B, Sun S. Dumbbell-like Au-Fe304 Nanoparticles for Target-Specific Platin Delivery. J Am Chem Soc. 2009;131:4216-7.

17. Sotiriou GA, Hirt AM, Lozach P-Y, Teleki A, Krumeich F, Pratsinis SE. Hybrid, Silica-Coated, Janus-Like Plasmonic-Magnetic Nanoparticles. Chem Mater. 2011;23:1985-92.

18. Zeng $H$, Sun S. Syntheses, properties and potential applications of multicomponent magnetic nanoparticles. Adv Funct Mater. 2008;18:391-400.

19. Chang B, Guo J, Liu C, Qian J, Yang W. Surface functionalization of magnetic mesoporous silica nanoparticles for controlled drug release. J Mater Chem. 2010;20:9941-7. 
20. Boedtkjer E, Pedersen S. The Acidic Tumor Microenvironment as a Driver of Cancer. Annu Rev Physiol. 2020;82:103-26.

21. Mahdavi M, Bin Ahmad M, Haron MJ, Namvar F, Nadi B, Ab Rahman MZ, Amin J. Synthesis, Surface Modification and Characterisation of Biocompatible Magnetic Iron Oxide Nanoparticles for Biomedical Applications. Molecules. 2013;18:7533-48.

Figures
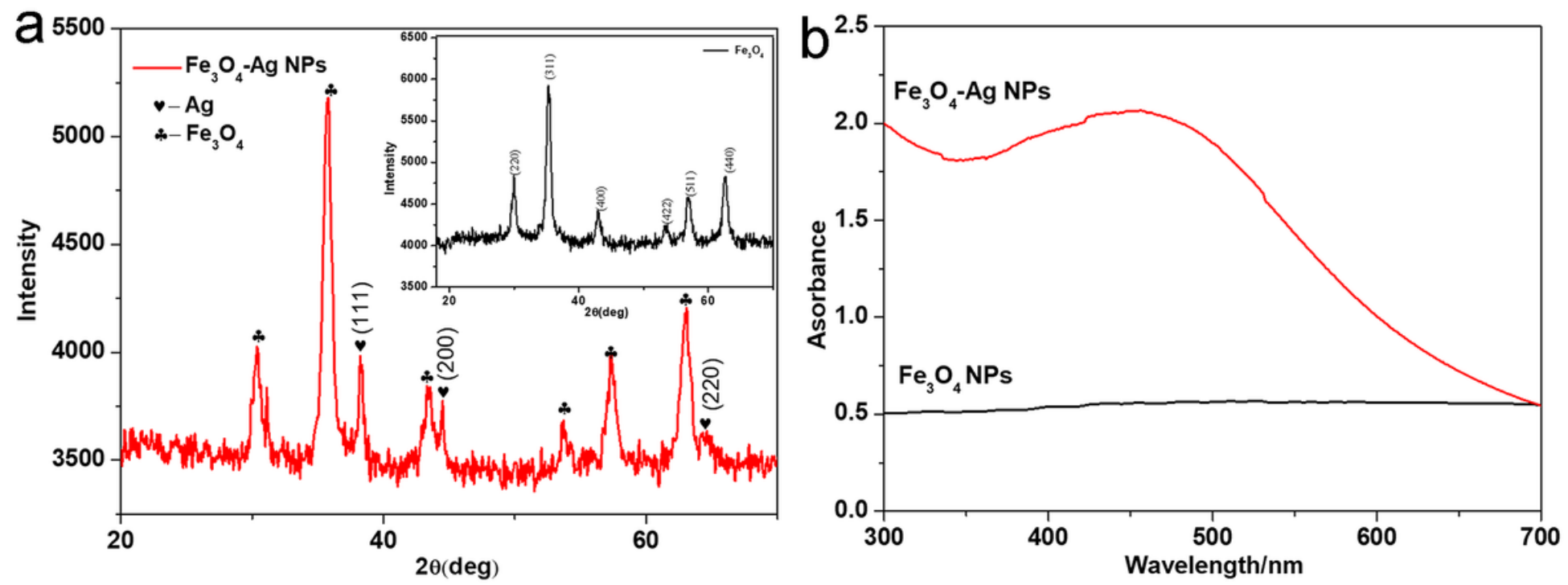

Figure 1

XRD and UV-vis spectra of Fe304 and Fe304-Ag NPs. (a) Small-angle XRD pattern of Fe304-Ag heterodimer NPs, insert shows the XRD pattern of Fe304 NPs, (b) UV-vis absorption spectra of Fe304 NPs and Fe304-Ag heterodimer NPs.
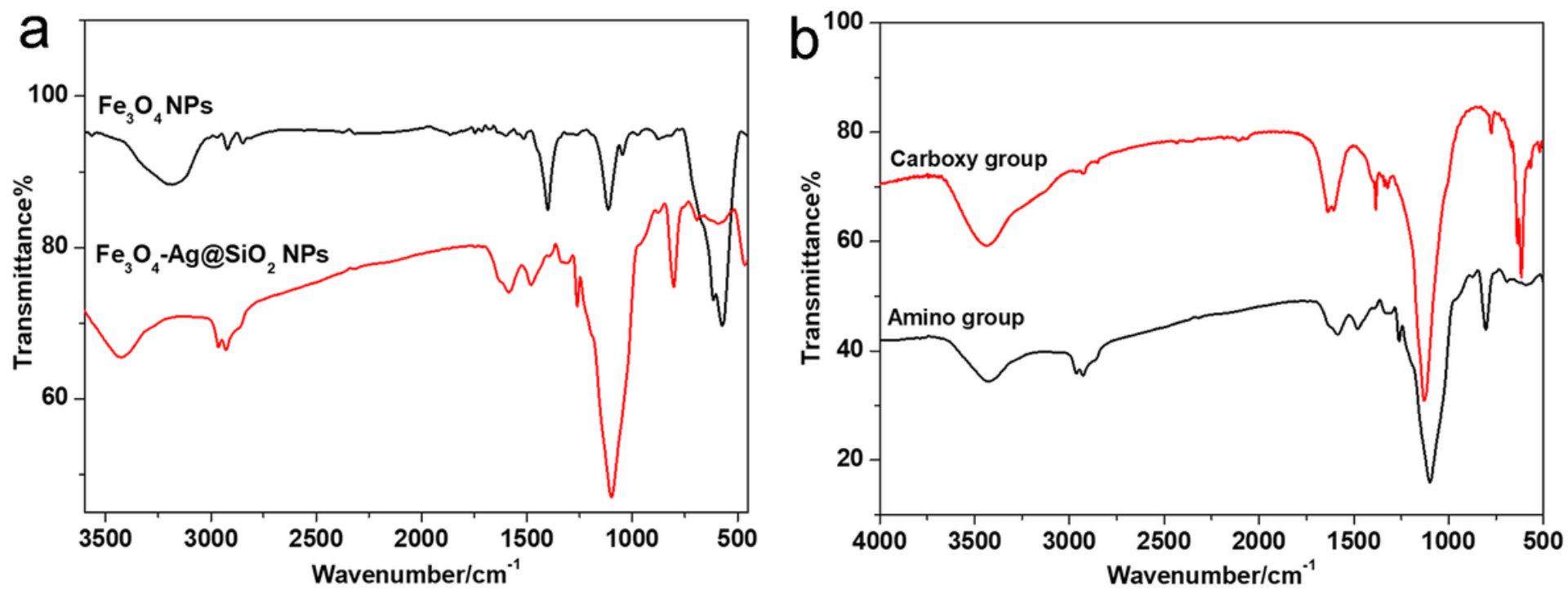

Figure 2 
FT-IR spectra of different particles. (a) FT-IR spectra of Fe304 NPs and Fe304-Ag@SiO2 NPs, (b) FT-IR spectra of Fe304-Ag@SiO2 NPs modified with amino or carboxyl groups on the surface.

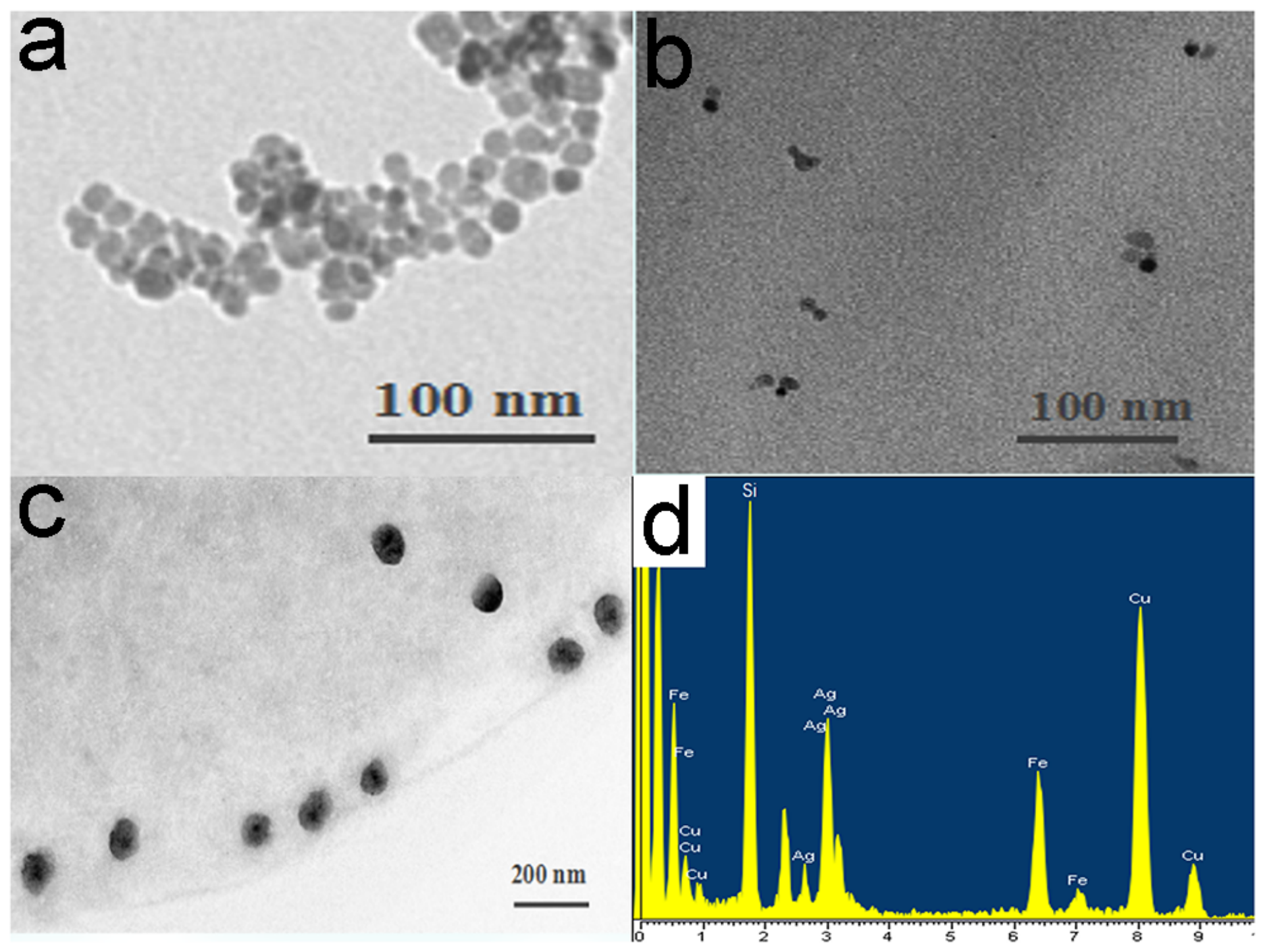

Figure 3

TEM images and EDS elemental analysis. (a) TEM image of Fe304 NPs, (b) TEM image of Fe304-Ag NPs, (c) TEM image of Fe304-Ag@SiO2 NPs, (d) EDS elemental analysis of Fe304-Ag@SiO2 NPs. 


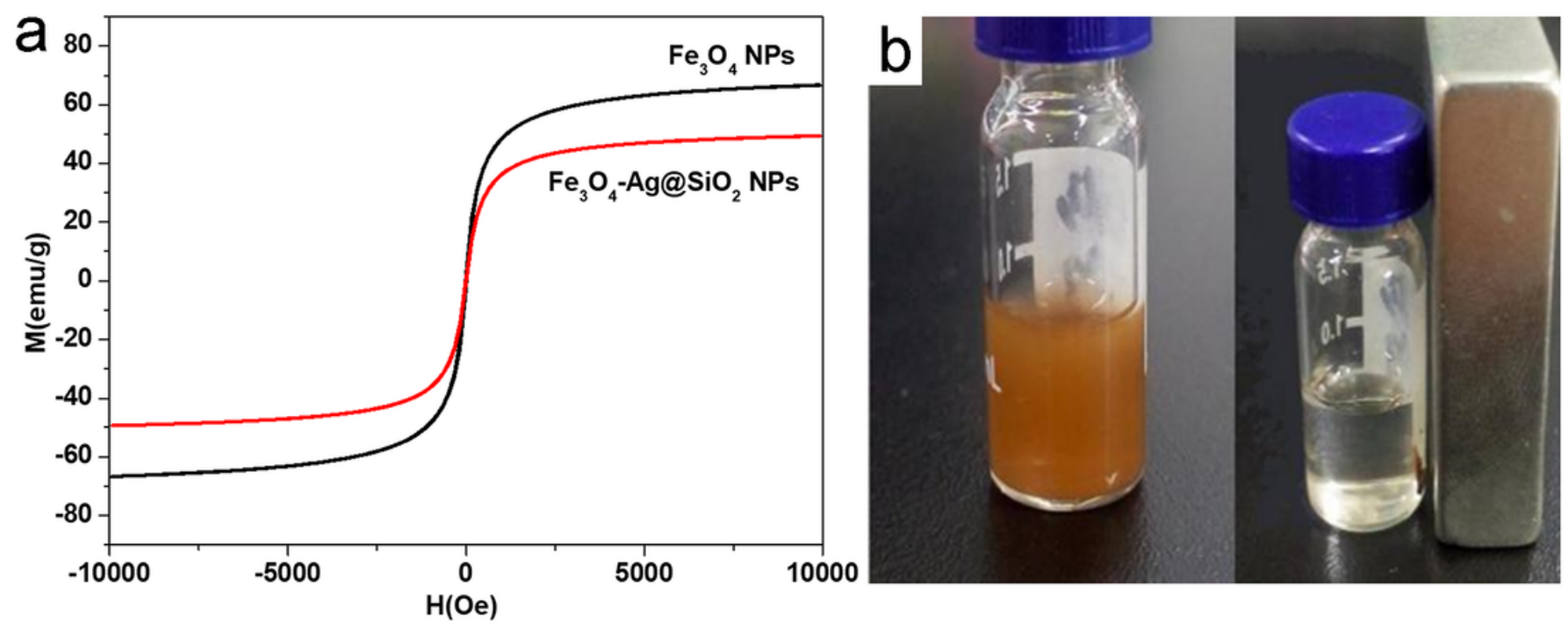

Figure 4

Magnetic property of Fe304-Ag@SiO2 NPs. (a) Magnetic hysteresis loop diagrams of Fe304 NPs and Fe304-Ag@SiO2 NPs, (b) magnetic manipulation of Fe304-Ag@SiO2 NPs.
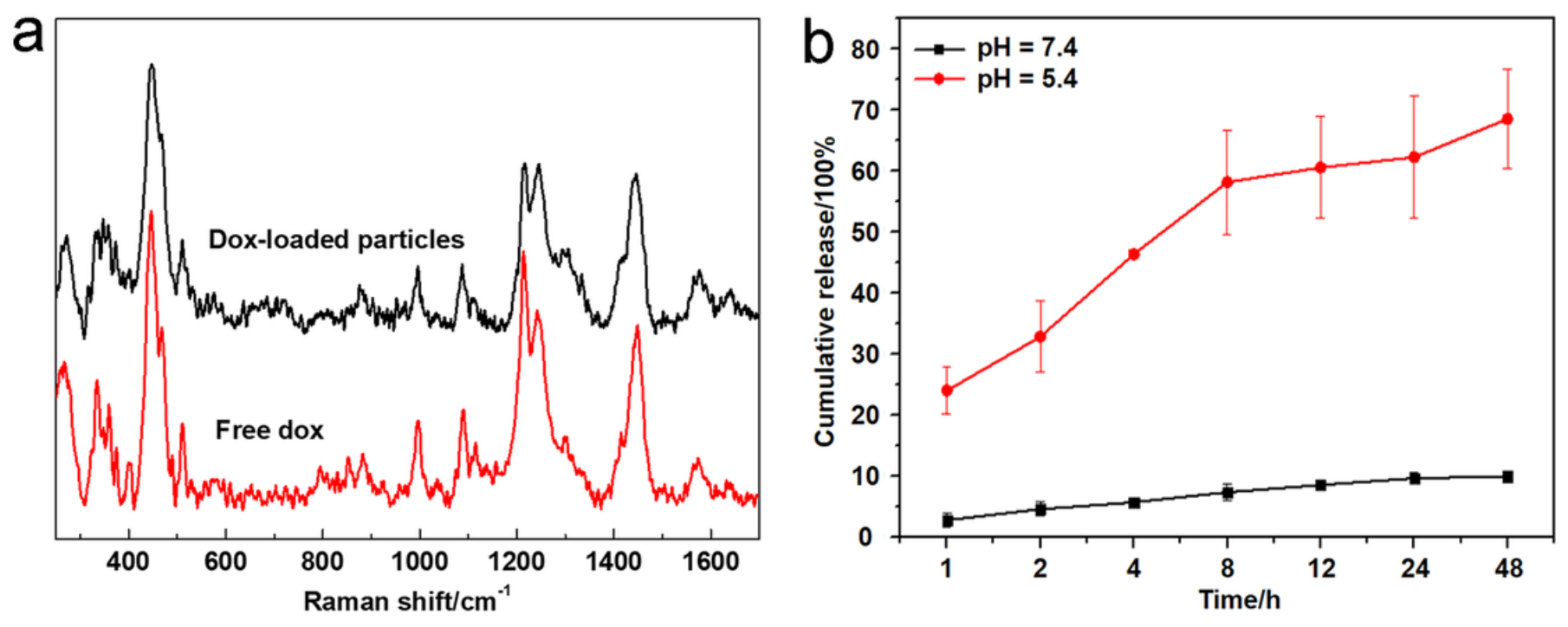

Figure 5

Drug loading and releasing performances of the particles. (a) Raman spectra of DOX and DOX-loaded NPs, (b) in vitro release curves of drug-loaded Fe304-Ag@SiO2 NPs in different pH conditions. 


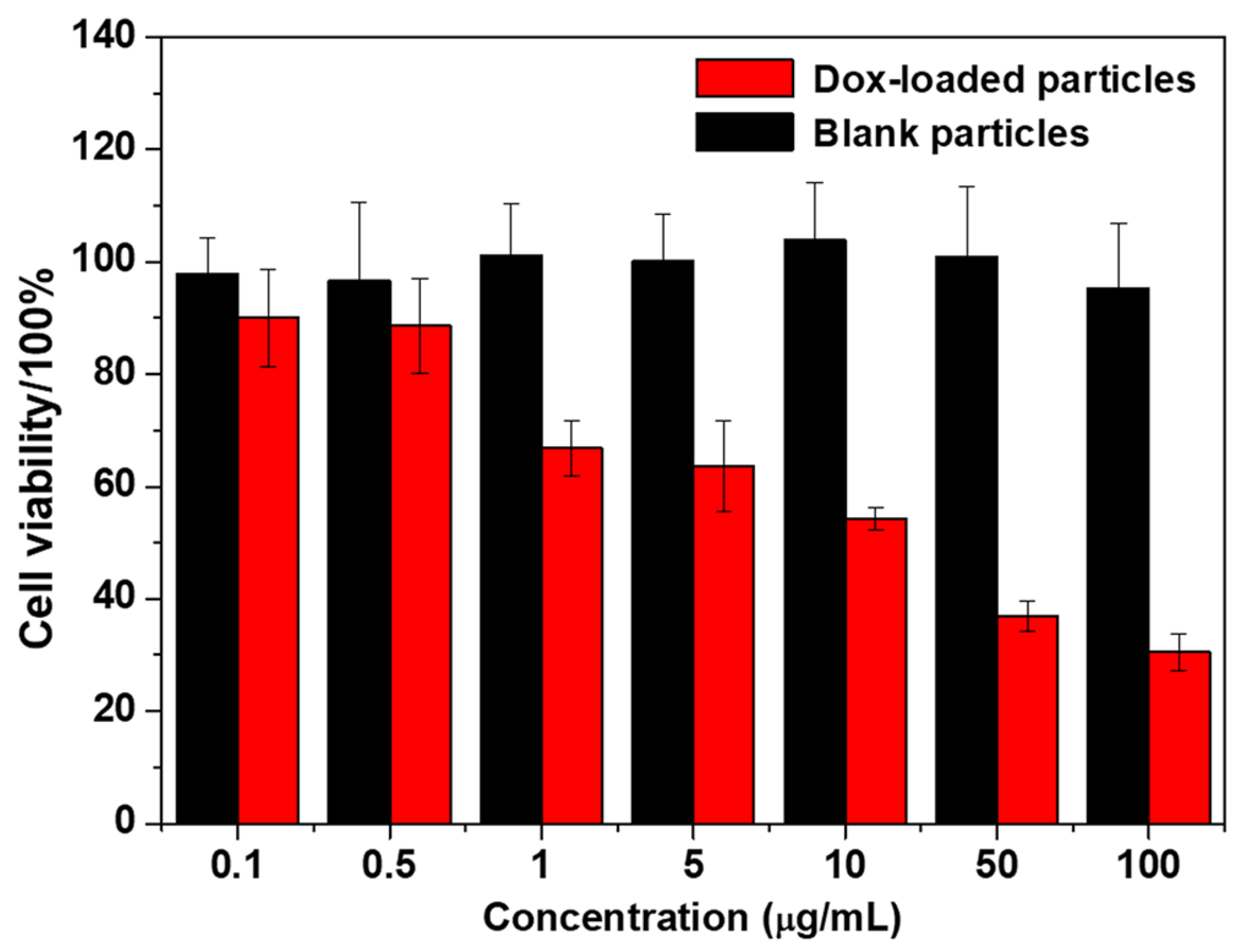

Figure 6

Apoptosis performance of the particles. MCF-7 Cells were incubated with different concentrations of Fe304-Ag@SiO2 NPs and DOX-loaded NPs for 24 h. 


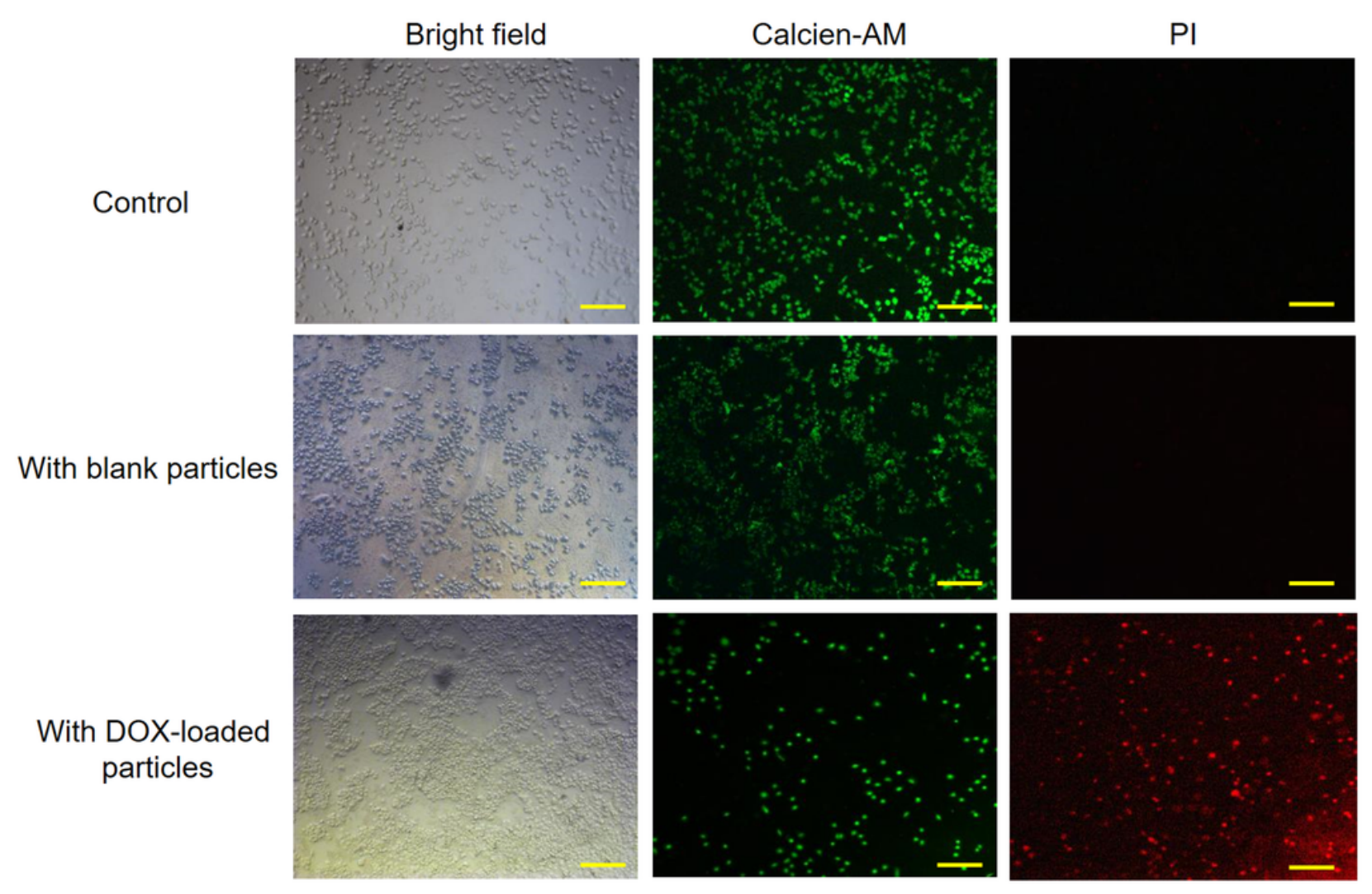

Figure 7

Bright field and fluorescent images of MCF-7 cells. Cells were cultured with blank Fe304-Ag@SiO2 NPs and DOX-loaded Fe304-Ag@SiO2 NPs, scale bars represent $50 \mu \mathrm{m}$ in all the images.

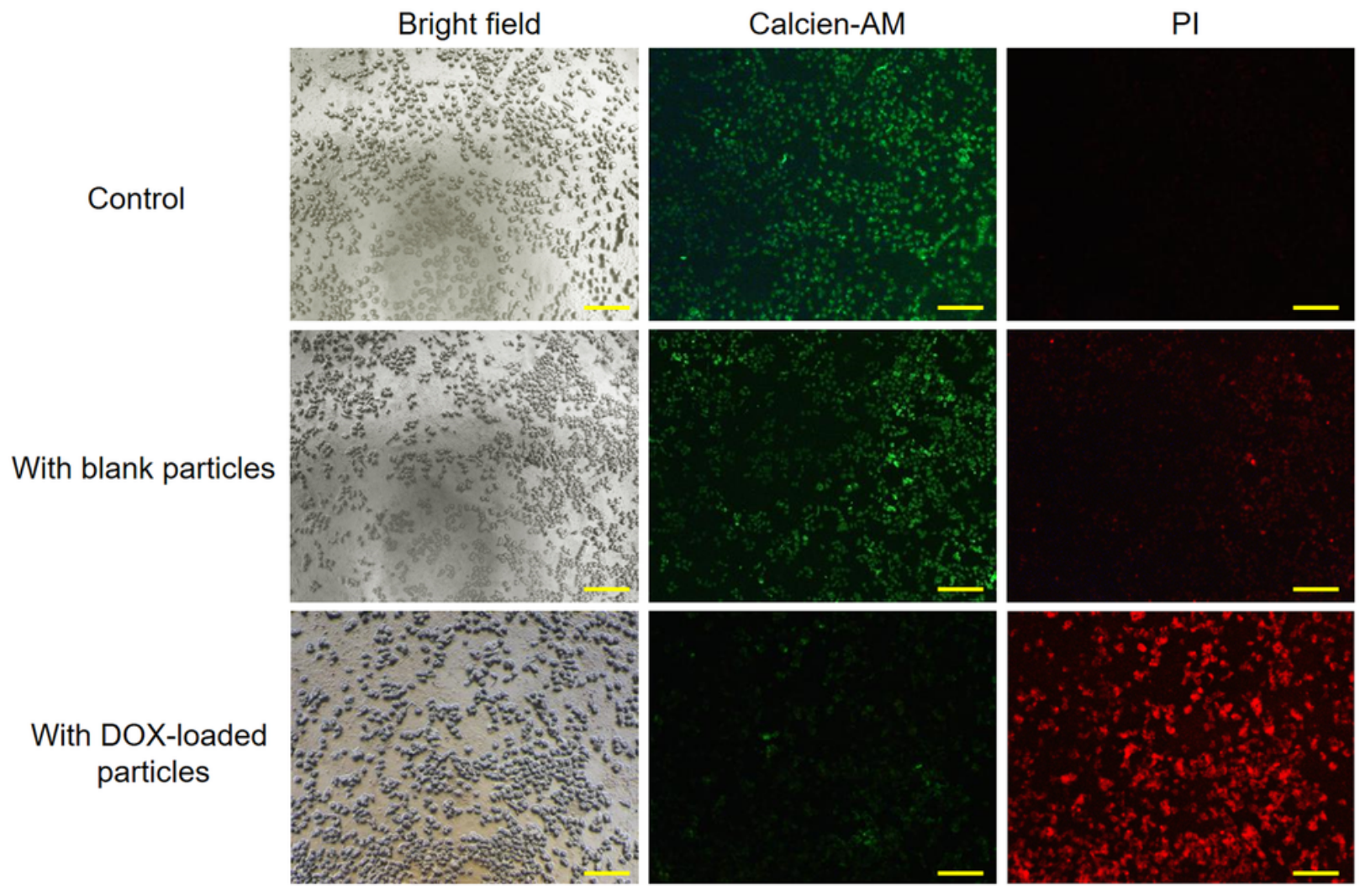


Figure 8

Bright field and fluorescent images of MCF-7 cells. Cells were cultured with blank Fe304-Ag@SiO2 NPs and DOX-loaded Fe304-Ag@SiO2 NPs after NIR laser irradiation, scale bars represent $50 \mu \mathrm{m}$ in all the images.

\section{Supplementary Files}

This is a list of supplementary files associated with this preprint. Click to download.

- GraphicalAbstract.png

- scheme1.png 